\title{
Influence of Humidity on Fiber Bragg Grating Sensors
}

\author{
Ander Montero, ${ }^{1}$ Gotzon Aldabaldetreku, ${ }^{2}$ Gaizka Durana, ${ }^{2}$ \\ Iagoba Jorge, ${ }^{1}$ Idurre Sáez de Ocáriz, ${ }^{1}$ and Joseba Zubia ${ }^{2}$ \\ ${ }^{1}$ Aeronautical Technologies Center (CTA), C/Juan de la Cierva, No.1 Parque Tecnológico de Álava, Miñano, 01510 Álava, Spain \\ ${ }^{2}$ Department of Communications Engineering, Faculty of Engineering, University of the Basque Country (UPV/EHU), \\ C/Alda. Urquijo S/N, 48013 Bilbao, Spain
}

Correspondence should be addressed to Ander Montero; ander.montero@ctaero.com

Received 5 September 2013; Revised 18 November 2013; Accepted 19 November 2013; Published 22 January 2014

Academic Editor: Xinyong Dong

Copyright (C) 2014 Ander Montero et al. This is an open access article distributed under the Creative Commons Attribution License, which permits unrestricted use, distribution, and reproduction in any medium, provided the original work is properly cited.

\begin{abstract}
We demonstrate the influence of the relative humidity (RH) on the wavelength of fiber Bragg grating sensors (FBGS), performing tests with five FBGS at different humidity and temperature conditions. These tests were performed in a climate chamber whose RH changes according to a scheduled profile from $30 \%$ to $90 \%$, in steps of $10 \%$. These profiles were repeated for a wide range of temperatures from $10^{\circ} \mathrm{C}$ to $70^{\circ} \mathrm{C}$, in steps of $10^{\circ} \mathrm{C}$. Two different types of instrumentation methods have been tested, spot welding and epoxy bonding, in two different materials, steel and carbon fiber reinforced polymer (CFRP). We discuss the results for each type of sensor and instrumentation method by analyzing the linearity of the Bragg wavelength with $\mathrm{RH}$ and temperature.
\end{abstract}

\section{Introduction}

Optical fiber sensors are one of the most suitable options for aircraft structural health monitoring (SHM) systems due to the advantages they offer: immunity to electromagnetic noise, with the consequent increase of safety and a better protection against loss of information; little weight compared with traditional monitoring systems, leading to a reduction of fuel consumption; and wide working temperature ranges [1]. At present, the application areas for fiber sensors are increasing; they can be used for corrosion monitoring in metallic components, carbon fiber reinforced polymers (CFRP), aircraft components health monitoring, sensing pressure, temperature, or microelectromechanical systems (MEMS) accelerometers [2], impact detection, vibration and strain measurement, or static strain temperatures.

An optical fiber is composed by a core, a thin strand of glass material that transmits light with very low loss, a cladding that reflects stray light back into the core, and a buffer coating that protects the fiber. A fiber Bragg grating (FBG) sensor consists of an ultraviolet (UV) periodic inscription, where a short length of photosensitive fiber is exposed to a periodic distribution of light intensity. As a consequence, the refractive index is altered according to light intensity, resulting in a periodic variation of the refractive index along the core.

When a broad-spectrum light is sent to an FBG core, a certain wavelength of this light is reflected, called Bragg wavelength, allowing the rest of the incoming light to pass through without additional modification [3]. This reflected Bragg wavelength changes according to the applied strain and to temperature conditions. In order to separate the temperature effect from the strain we have used a not bonded FBG as a reference so that we could subtract this temperature effect from the FBGS bonded in the specimen [4]. With this procedure the measurement of the real strain on the sample is assured.

The Bragg wavelength $\left(\lambda_{B}\right)$ reflected by each FBG sensor can be calculated as follows:

$$
\lambda_{B}=2 n_{\mathrm{eff}} \Lambda,
$$

where $n_{\text {eff }}$ is the effective refractive index of the fiber core and $\Lambda$ is the pitch of the grating.

Changes in strain $(\Delta \varepsilon)$ or temperature $(\Delta T)$ produce a shift in the pitch of the grating $(\Delta \Lambda)$, which can be observed by measuring the corresponding changes in the wavelength of 


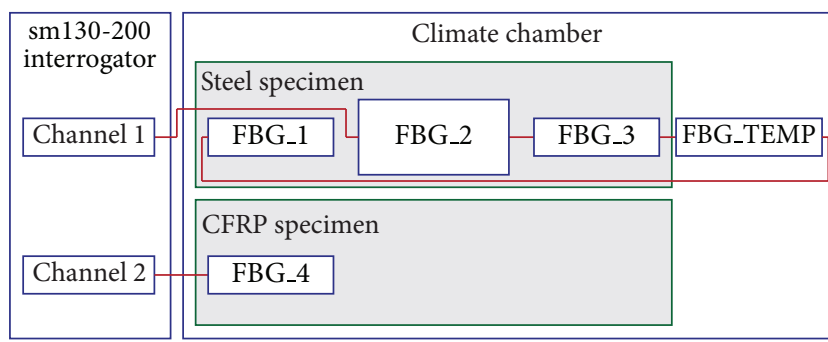

FIGURE 1: Layout of the specimens used in the study.

the reflected light. The equation that relates all these changes is

$$
\Delta \lambda_{B}=K_{\varepsilon} \Delta_{\varepsilon}+K_{T} \Delta_{T},
$$

where $K_{\varepsilon}$ is the strain coefficient and $K_{T}$ is the temperature coefficient.

In this study we have measured the wavelength shift of five FBGS in a climate chamber, whose RH changed at a constant temperature. We have also repeated the tests at different temperature conditions. The FBGS tested were manufactured by Micron Optics and the model sm130-200 was used as the interrogator device [5].

According to the manufacturer, the wavelength to strain relation can be separated from the temperature response in the following way [6]:

$$
\varepsilon=\frac{\Delta \lambda}{\lambda_{0}} \cdot \frac{10^{6}}{F_{G}}-\varepsilon_{T_{0}}
$$

where thermal output $\varepsilon_{T_{0}}$ (thermally induced apparent strain) is:

$$
\varepsilon_{T_{0}}=\Delta T\left(\frac{C_{1}}{F_{G}}+\mathrm{CTE}_{S}-C_{2}\right)
$$

$\Delta \lambda$ is the wavelength observed, $\lambda_{0}$ is the nominal FBG wavelength at $22^{\circ} \mathrm{C}$, and $\Delta T$ is the temperature change inside the climate chamber. $F_{G}$ is a dimensionless gauge factor, $C_{1}$ and $\mathrm{C}_{2}$ are temperature gage constants $\left(\right.$ in $\mu \mathrm{m} / \mathrm{m} \cdot{ }^{\circ} \mathrm{C}$ ), and $\mathrm{CTE}_{s}$ is the coefficient of thermal expansion of the material on which each FBG is instrumented.

Thus, any serious measurement should take into account this thermal output in order to separate the thermally induced apparent strain from the mechanically induced strain on the specimen, with the latter being the real aim of the measurement. However, it is not clear whether additional environment variations (such as changes in RH) could also have an effect on the measurement itself. For this reason, it is our purpose to analyze the wavelength shift at different humidity and temperature conditions without inducing any mechanical strain.

Few studies have been carried out to calculate the effect of RH on FBGS. For instance, Giaccari et al. studied the influence of humidity and temperature on polyimide-coated fiber Bragg gratings and the effect of this coating on Bragg wavelengths [7]. In another study Correia et al. developed a

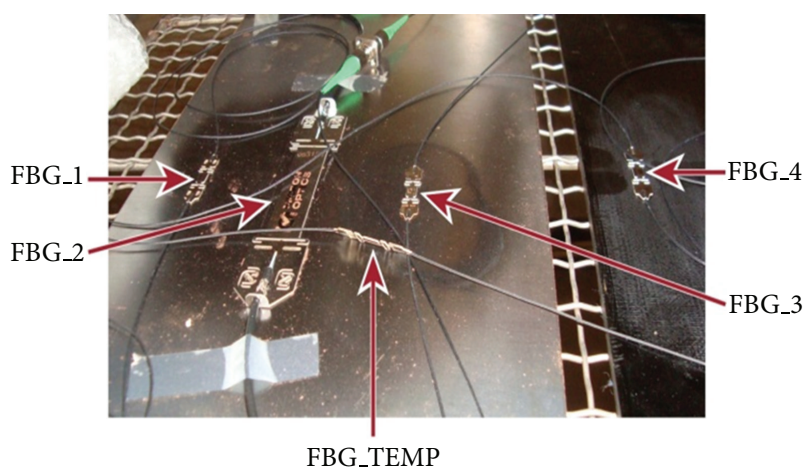

Figure 2: FBGS instrumented in the steel and CFRP specimens.

RH sensor based on a Bragg grating coated with an organosilica di-ureasil hybrid material, demonstrating its viability for civil engineering purposes [8].

For this reason, we have conducted this study in order to clarify and quantify the behavior of FBG sensors with changes in the $\mathrm{RH}$ at different temperatures, FBG bonding conditions, and specimen materials, separating the effect that the RH has on each element. We believe that the effect of the RH should not be neglected to avoid misreadings.

\section{Materials and Methods}

In this experimental program we will measure the influence of humidity on five different FBG sensors. RH conditions were varied from $30 \% \mathrm{RH}$ to $90 \% \mathrm{RH}$ in steps of $10 \% \mathrm{RH}$ at a constant temperature. These $\mathrm{RH}$ series were repeated for different temperatures ranging from $10^{\circ} \mathrm{C}$ to $70^{\circ} \mathrm{C}$, in steps of $10^{\circ} \mathrm{C}$. It should be mentioned that instead of $20^{\circ} \mathrm{C}$, we have set the climate chamber to $22^{\circ} \mathrm{C}$ in order to make it coincide with the temperature where the nominal wavelength of each FBG is taken as a reference. Nevertheless, due to the working limitations of the climate chamber not all the possible RH and temperature combinations could be achieved.

Two specimens have been tested; one steel rectangular sample and another CFRP rectangular sample. The test layout is shown in Figure 1; as it can be seen, we use separate channels of the interrogator for each specimen: channel one for the three steel specimen FBGS and for the temperature compensation FBG, and channel two for the CFRP specimen FBG. The base material of each specimen requires a different FBG instrumentation method for a correct measurement: either spot welding or epoxy bonding for the steel specimen and epoxy bonding for the CFRP specimen.

Figure 2 shows a photograph of the five FBGS instrumented in the specimens. Table 1 summarizes the FBGS, their features, the base material of their corresponding specimens, and their instrumentation methods.

Figure 3 shows with more detail each instrumentation method, namely, the spot welding and the epoxy bonding. On the spot welded FBG_2 there are 14 spot welds on each side of the covering, and they have been performed according to the indications given by the manufacturer using a specific spot welding device. The spot welds in FBG_2 and the epoxy 
TABle 1: Parameters of the FBG sensors.

\begin{tabular}{|c|c|c|c|c|c|c|c|}
\hline \multirow{2}{*}{ FBG ID } & \multirow{2}{*}{ FBG model } & \multirow{2}{*}{ Specimen material } & \multirow{2}{*}{ Bonding method } & \multicolumn{4}{|c|}{ Constants } \\
\hline & & & & $F_{G}$ & $C_{1}$ & $\mathrm{C}_{2}$ & $\lambda_{0}\left(22^{\circ} \mathrm{C}\right)$ \\
\hline FBG_1 & os3110 & Steel & Spot-welded & 0.89 & 6.156 & 0.70 & 1552.013 \\
\hline FBG_2 & os3150 & Steel & Spot-welded & 0.797 & 6.156 & 0.70 & 1572.355 \\
\hline FBG_3 & os3120 & Steel & Epoxy bonded & 1.00 & 6.156 & 0.70 & 1540.223 \\
\hline FBG_4 & os3120 & CFRP & Epoxy bonded & 1.00 & 6.156 & 0.70 & 1540.462 \\
\hline FBG_TEMP & os 3120 & - & $\begin{array}{l}\text { Not bonded (for } T \\
\text { compensation) }\end{array}$ & 1.00 & 6.156 & 0.70 & 1524.415 \\
\hline
\end{tabular}

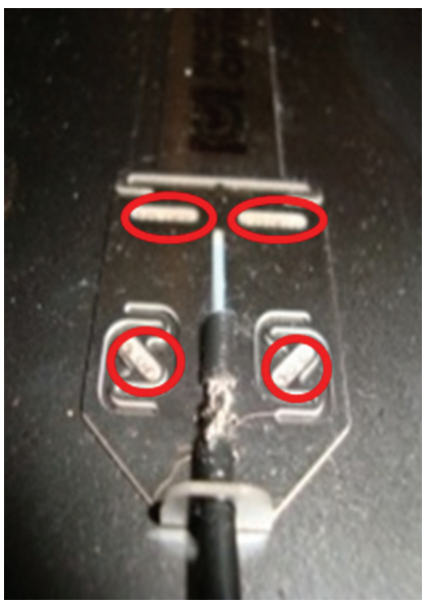

(a)

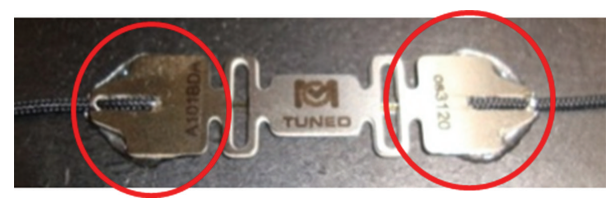

(b)

Figure 3: Instrumentation methods applied to each specimen. (a) FBG_2 is spot welded to steel specimen. (b) FBG_4 is epoxy bonded to CFRP specimen.

bonding areas in FBG_4 are marked with red circles in Figure 3.

Tests started at $70^{\circ} \mathrm{C}$ and $30 \% \mathrm{RH}$, increasing the $\mathrm{RH}$ in steps of $10 \%$ until $90 \% \mathrm{RH}$ has been reached (the temperature was constant during these steps). Afterwards, the temperature has been decreased to $60^{\circ} \mathrm{C}$ at a constant $\mathrm{RH}(90 \%)$. Once this new temperature has been stabilized, the $\mathrm{RH}$ has been decreased in steps of $10 \%$ until $30 \% \mathrm{RH}$ has been reached (corresponding to the lower limit attainable by the climate chamber). We have used the same procedure for the rest of the temperatures (i.e., $50^{\circ} \mathrm{C}, 40^{\circ} \mathrm{C}, 30^{\circ} \mathrm{C}, 22^{\circ} \mathrm{C}$, and $10^{\circ} \mathrm{C}$ ): we have changed the $\mathrm{RH}$ in steps of $10 \%$ between the extreme values of the $\mathrm{RH}$ (i.e., $30 \%$ and $90 \% \mathrm{RH}$ ).

Between each step a stabilization time has been given in order to steady the wavelengths from FBGS. This stabilization time is compulsory in most cases due to the effect of the humidity on CFRP materials [9] and on epoxy bonding [10]. This effect is plainly visible in the response of the FBG_3 and FBG_4 sensors, whose stabilization time is very high. The other FBGS suffer from the same effect, but on a smaller scale. These results will be discussed in the following section.

Due to small temperature fluctuations in the climate chamber, significant variations of the Bragg wavelength $\left(\lambda_{B}\right)$ are obtained. To avoid this undesirable effect, a compensating wavelength has been calculated for each temperature fluctuation. This compensation consists of removing the wavelength variation corresponding to the temperature fluctuation. For this purpose, (3) and (4) are used (by setting $\varepsilon$ to zero that is, no mechanical strain is applied), obtaining:

$$
\begin{aligned}
\lambda_{\text {compensed }}= & \lambda_{\text {obtained }}-\left(T_{\text {Real }}-T_{\text {Ref }}\right) \cdot \\
& \cdot\left(\frac{C_{1}}{F_{G}}+\mathrm{CTE}_{S}-C_{2}\right) \cdot \frac{\lambda_{0} \cdot F_{G}}{10^{6}} .
\end{aligned}
$$

The importance of compensating the temperature fluctuations can be illustrated by the following facts: if we select a temperature for the climate chamber, say $70^{\circ} \mathrm{C}$, we can expect a temperature departure up to $70.5^{\circ} \mathrm{C}$ during the set-up, which results in a wavelength shift of about $0.01 \mathrm{~nm}$. This shift and the wavelength shift due to a $10 \%$ variation in the $\mathrm{RH}$ are of the same order of magnitude (in fact, it can be seen that the Bragg wavelength can shift up to $0.015 \mathrm{~nm}$ for such a variation in the RH). Due to these variations it is impossible to neglect such small temperature fluctuations. Therefore, it is necessary to use the compensating method given by (5).

We have supplied the same time reference for both the FBG interrogator and the climate chamber acquiring system, ensuring a perfect correlation of the data acquired by both systems. 


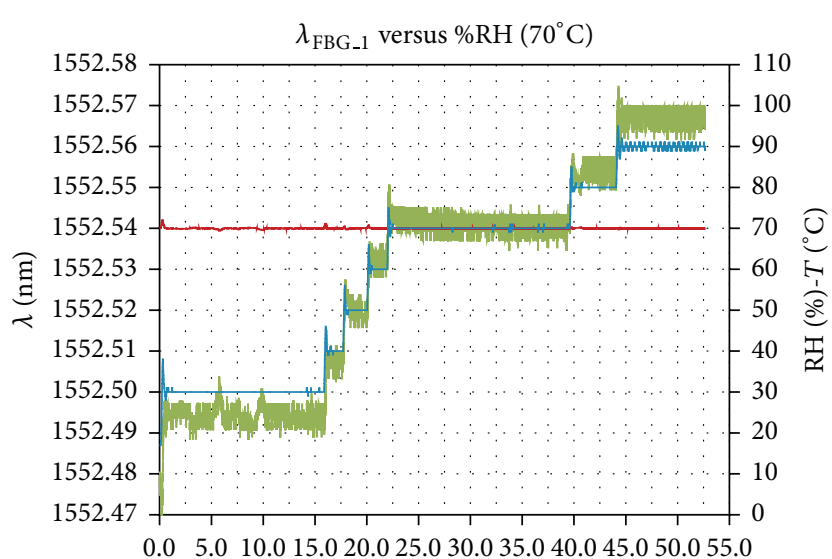

(h)

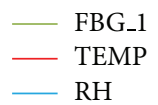

FIGURE 4: Bragg wavelength shift of FBG_1 (green, left axis) as a function of the $\% \mathrm{RH}$ (blue, right axis) at a temperature of $70^{\circ} \mathrm{C}$ (red, right axis).

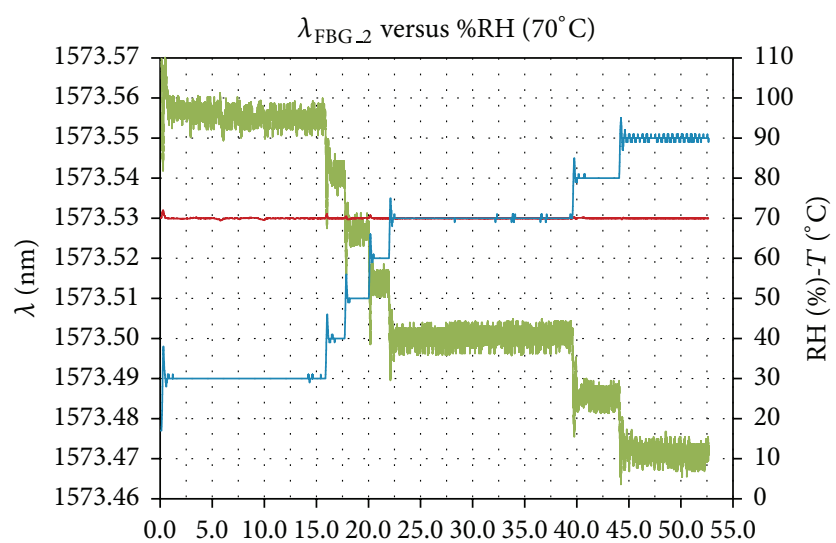

(h)

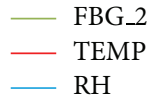

FIGURE 5: Bragg wavelength shift of FBG_2 (green, left axis) as a function of $\% \mathrm{RH}$ (blue, right axis) at a temperature of $70^{\circ} \mathrm{C}$ (red, right axis).

\section{Results and Discussion}

An almost linear variation in the Bragg wavelength has been obtained in some of the FBGS tested. More specifically, spot welded FBG_1 and FBG_2 show linear wavelength variations for proportional changes in the RH. FBG_TEMP also shows a linear variation in its Bragg wavelength for linear variations of the $\mathrm{RH}$, but it is much lower than in the case of FBG_1 or FBG_2. By contrast, FBG_3 and FBG_4 show a nonlinear behavior due to the absorption of humidity by epoxy adhesives [10] and composite materials [9].

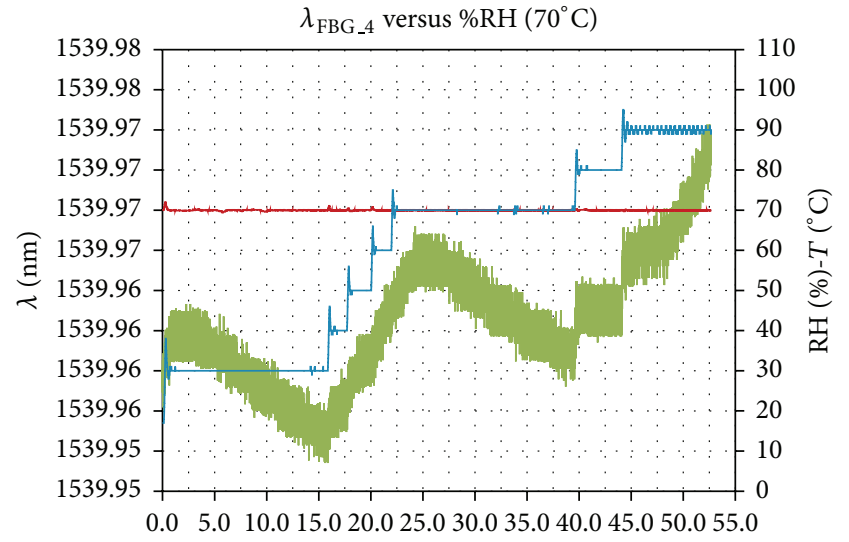

(h)

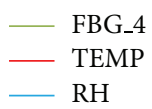

FIgURE 6: Bragg wavelength shift of FBG_4 (green, left axis) as a function of $\% \mathrm{RH}$ (blue, right axis) at a temperature of $70^{\circ} \mathrm{C}$ (red, right axis).

First of all, we see in Figure 4 the results obtained for FBG_1. A linear dependence of the Bragg wavelength on humidity can be seen. These $\lambda_{\text {FBG_1 }}$ values include the temperature compensation given in (5). In order to check whether the $\lambda_{\text {FBG_1 }}$ Bragg wavelength suffers from hysteresis or not (i.e., whether the $\lambda_{\text {FBG_1 }}$ depends or not on the sequence followed in the variation of the $\mathrm{RH}$ ), we have repeated this test for a different sequence of variations of the RH. Results obtained confirm that $\lambda_{\text {FBG_1 }}, \lambda_{\mathrm{FBG}_{-} 2}$, and $\lambda_{\text {FBG_TEMP }}$ show no hysteresis at all, ensuring the repeatability of the test.

The results obtained for FBG_2 are shown in Figure 5. Just as in the case of FBG_1, the response of FBG_2 is practically instantaneous and linear. As can be seen in Figure 5, this response has the opposite tendency than the expected; $\lambda_{\mathrm{FBG}_{2} 2}$ decreases with increasing RH. Before being able to find an explanation to such contradictory trends, it will be necessary to analyze the results of the rest of FBG sensors. This analysis can be found at the end of this section.

As to the response of FBG_3, it is not as instantaneous as in the cases of FBG_1 or FBG_2 due to the epoxy bonding instrumentation method used. FBG_3 takes more time to stabilize the wavelength than FBG_1 and FBG_2; in some cases this stabilization time is up to 24 hours. The same phenomenon occurs with FBG_4 (shown in Figure 6), but in this case the effect of humidity on the CFRP has to be added, which is higher than on an epoxy adhesive [10].

For the temperature compensation sensor (FBG_TEMP), notice that in Figure $7 \lambda_{\text {FBG_TEMP }}$ decreases with increasing $\mathrm{RH}$, in the same way as in FBG_2. Again, we have found a linear variation of its Bragg wavelength with the RH. Although this variation is less significant than in the other sensors, it should be taken into account for correct temperature compensation, in order to remove this $\mathrm{RH}$ effect.

Figure 8 summarizes the results obtained for the sensors, showing a linear dependence of the wavelength shift on $\mathrm{RH}$, 


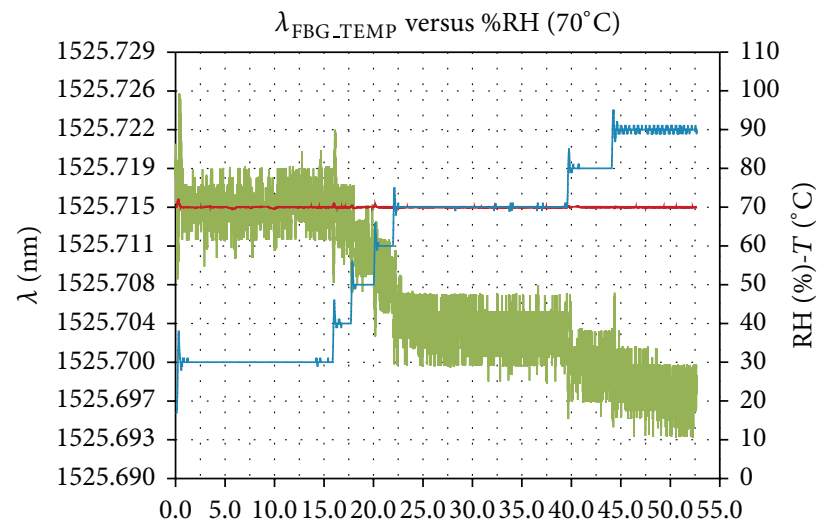

(h)

- FBG_TEMP
- TEMP
- RH

FIGURE 7: Bragg wavelength shift of FBG_TEMP (green, left axis) as a function of $\% \mathrm{RH}$ (blue, right axis) at a temperature of $70^{\circ} \mathrm{C}$ (red, right axis).

that is, for sensors FBG_1, FBG_2, and FBG_TEMP. For each temperature the FBGS have been exposed to a wide range of $\mathrm{RH}$ conditions. Due to the climate chamber some of the $\mathrm{RH}$ conditions are not exactly the same for all the temperatures (i.e., in $10^{\circ} \mathrm{C}$ an $\mathrm{RH}$ minor to $50 \%$ could not be reached). Additionally, it should be mentioned that instead of $20^{\circ} \mathrm{C}$, we have set the climate chamber to $22^{\circ} \mathrm{C}$ in order to make it coincide with the temperature where the nominal wavelength of each FBG is taken as a reference. At a first glance, the linear dependence of the wavelength shift with $\mathrm{RH}$ is smaller in the FBG_TEMP sensor, since there is no effect of any specimen at all.

We have performed a least square fit to relate the Bragg wavelength shift to the RH for FBG_1, FBG_2, and FBG TEMP sensors. We have calculated the typical errors of the linear fit for each temperature and $\mathrm{RH}$, obtaining an average error of $0.42 \%$, so that we can safely assume a linear dependence on $\mathrm{RH}$. The value of the coefficient of determination $R^{2}$ has been calculated for each regression; for FBG_1, FBG_2 and FBG_TEMP the average of $R^{2}$ is $0.996,0.990$, and 0.887 , respectively.

We have calculated the coefficients of the approaching linear polynomials for each sensor at each temperature. These coefficients show little deviations at different $\mathrm{RH}$ in the same sensor. The following equations show the relationship found between $\lambda_{B}$ and RH for FBG_1, FBG_2, and FBG_TEMP (the only sensors showing a linear dependence):

$$
\begin{aligned}
\lambda_{\mathrm{FBG}_{2}(\mathrm{~nm})=} & (1551.7173 \pm 0.0107) \\
& +(0.0104 \pm 0.0002) \cdot T\left({ }^{\circ} \mathrm{C}\right) \\
& +(0.001375 \pm 0.000071) \cdot \mathrm{RH}(\%), \\
\lambda_{\mathrm{FBG}_{2}}(\mathrm{~nm})= & (1571.8805 \pm 0.0140) \\
& +(0.0244 \pm 0.0003) \cdot T\left({ }^{\circ} \mathrm{C}\right) \\
& -(0.001410 \pm 0.000067) \cdot \mathrm{RH}(\%),
\end{aligned}
$$

$$
\begin{aligned}
\lambda_{\mathrm{FBG}_{-} \mathrm{TEMP}}(\mathrm{nm})= & (1523.8299 \pm 0.01174) \\
& +(0.0269 \pm 0.0003) \cdot T\left({ }^{\circ} \mathrm{C}\right) \\
& -(0.000200 \pm 0.000120) \cdot \mathrm{RH}(\%)
\end{aligned}
$$

(Results obtained for the sensor FBG_1 should be taken with caution for reason given below).

From the previous expressions, it is clear that the $\lambda_{B}$ Bragg wavelength depends slightly on the RH (if compared to the effects of the temperature variation). In order to estimate the $\mathrm{RH}$ compensation that we should apply to our measurements, we could proceed as follows: we would calculate the equivalent temperature change $\Delta T$ that would yield the same wavelength shift. For such a purpose, we would substitute (4) into (3) and, by setting $\varepsilon$ to zero (no mechanical strain is applied), we would obtain

$$
\Delta T=\frac{\left(\Delta \lambda / \lambda_{0}\right)\left(10^{6} / F_{G}\right)}{\left(C_{1} / F_{G}\right)-\mathrm{CTE}_{S}+C_{2}} .
$$

This way, we could make use of (5) to apply the required compensation for $\mathrm{RH}$ fluctuations. At situations where the environment conditions change continuously, we can expect variations in the $\mathrm{RH}$ as high as $60 \%$, which would lead to a Bragg wavelength shift of $0.1 \mathrm{~nm}$ (if measured at a standard temperature of $60^{\circ} \mathrm{C}$ with FBG_2). As seen in Table 2 , such a wavelength would be equivalent to a temperature variation of $4.45^{\circ} \mathrm{C}$ (which would lead to an error in the strain measured to be of $31.26 \mu \mathrm{m} / \mathrm{m})$.

Let us now analyze the reasons for having a different behavior in the sensor FBG_1 as compared to sensors FBG_2, and FBG_TEMP (sensors FBG_3 and FBG_4 are not considered due to the preponderant effects of the epoxy bonding and CFRP specimen). For such a purpose, we have detached the FBG_1 and FBG_2 sensors from the specimen by removing the weld spots, and we have repeated the tests corresponding to $70^{\circ} \mathrm{C}$ and a variable range of $\mathrm{RH}$ from $30 \% \mathrm{RH}$ to $90 \% \mathrm{RH}$. Such a procedure enables us to separate the influence of the $\mathrm{RH}$ on the steel specimen and only measure the effect of the $\mathrm{RH}$ on the sensor. Figure 9 shows both sensors FBG_1 and FBG_2 after being detached from the specimen.

Figure 10 allows us to make a comparison between the results obtained for the sensor attached to the specimen and the same sensors after being removed from the specimen.

As it can be seen in Figure 10(a), the FBG_1 sensor shows an identical behavior irrespective of being or not being instrumented in the specimen. Instead, from Figure 10(b) the FBG_2 sensor shows a higher slope for the wavelength variation with the RH when instrumented to the specimen. The results for the FBG_1 sensor are unexpected because the effect of the RH on the steel specimen should have been removed.

This unexpected behavior forced us to perform an exhaustive inspection of both FBGS. The inspection showed that FBG_1 fiber was broken at one end of the Bragg grating. This break can be seen clearly in Figure 11.

Such a break explains why we did not obtain any signal when the FBG_1 sensor was connected to the interrogator 




(a)

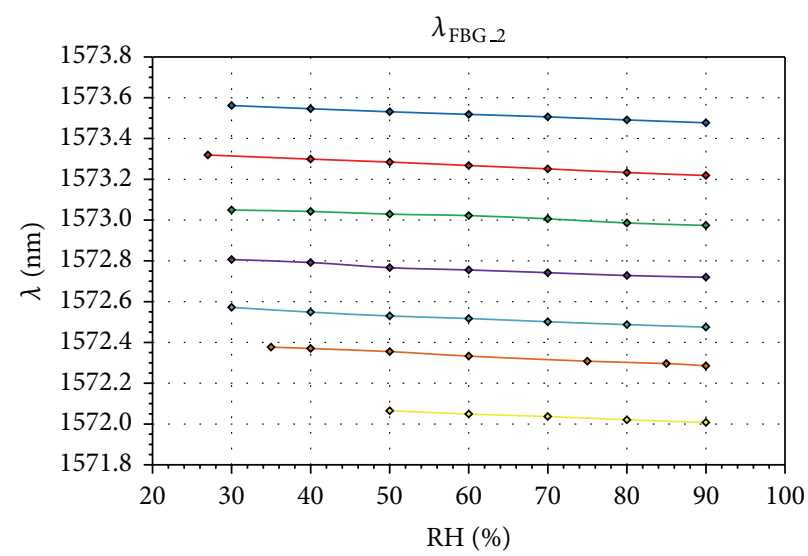

(b)

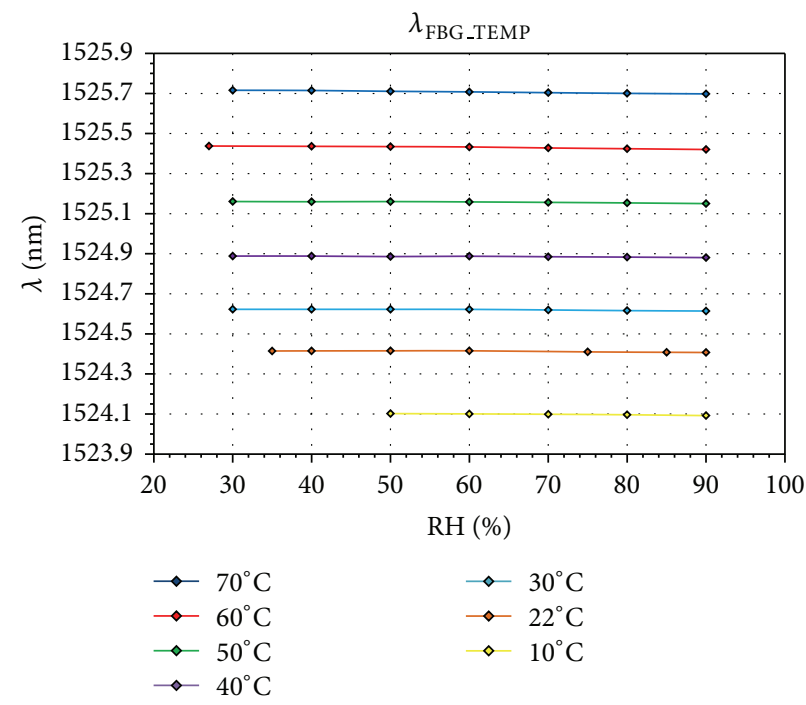

(c)

Figure 8: Linear fit to the Bragg wavelength shift with the RH for (a) FBG_1, (b) FBG_2, and (c) FBG_TEMP.



(a)

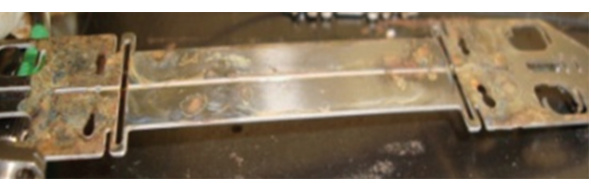

(b)

Figure 9: FBG_1 and FBG_2 without instrumentation to steel specimen.

from the broken side at our preliminary tests. Since we could measure wavelength shifts when the sensor was connected from the other side, we did not pay much attention to this anomaly and reconnected the FBG_1, FBG_2 and FBG_TEMP sensors following the order shown in Figure 1. Such a reconnection allowed us to obtain measurements from every sensor, since the broken end of FBG_1 was placed at the extreme of the array.

These results serve us to confirm that the graph of the FBG_1 sensor in Figure 4 shows only the influence of the RH on the coating of the FBG itself, since it is detached from the metallic carrier that holds the FBG in tension, avoiding the 


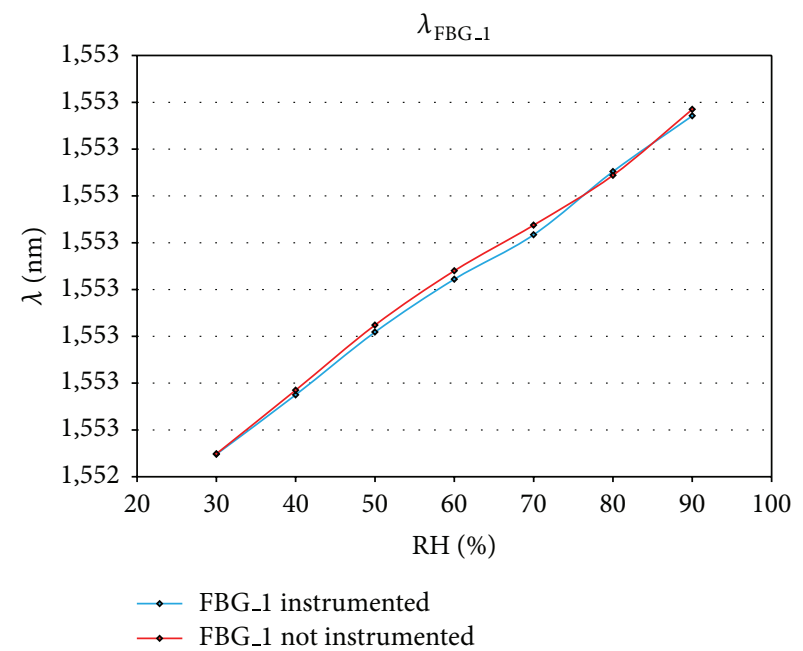

(a)



(b)

FIGURE 10: Wavelength shift with RH for instrumented and not instrumented sensors (a) FBG_1 and (b) FBG_2.

TABLE 2: Bragg wavelength shifts and equivalent temperature variation obtained at different measurement conditions for each FBG sensor.

\begin{tabular}{|c|c|c|c|c|}
\hline$T\left({ }^{\circ} \mathrm{C}\right)$ & & FBG_1 & FBG_2 & FBG_TEMP \\
\hline \multirow{4}{*}{70} & $\lambda_{30 \% \mathrm{RH}}(\mathrm{nm})$ & 1552.495 & 1573.562 & 1525.716 \\
\hline & $\lambda_{90 \% \mathrm{RH}}(\mathrm{nm})$ & 1552.567 & 1573.477 & 1525.698 \\
\hline & $\Delta \lambda(\mathrm{nm})$ & 0.072 & -0.085 & -0.018 \\
\hline & $\Delta T_{\mathrm{eq}}\left({ }^{\circ} \mathrm{C}\right)$ & 3.03 & -3.74 & -0.72 \\
\hline \multirow{4}{*}{60} & $\lambda_{27 \% \mathrm{RH}}(\mathrm{nm})$ & 1552.374 & 1573.319 & 1525.438 \\
\hline & $\lambda_{90 \% \mathrm{RH}}(\mathrm{nm})$ & 1552.460 & 1573.219 & 1525.420 \\
\hline & $\Delta \lambda(\mathrm{nm})$ & 0.087 & -0.100 & -0.018 \\
\hline & $\Delta T_{\mathrm{eq}}\left({ }^{\circ} \mathrm{C}\right)$ & 3.63 & -4.45 & -0.69 \\
\hline \multirow{4}{*}{50} & $\lambda_{30 \% \mathrm{RH}}(\mathrm{nm})$ & 1552.280 & 1573.049 & 1525.161 \\
\hline & $\lambda_{90 \% \mathrm{RH}}(\mathrm{nm})$ & 1552.353 & 1572.974 & 1525.150 \\
\hline & $\Delta \lambda(\mathrm{nm})$ & 0.051 & -0.055 & -0.010 \\
\hline & $\Delta T_{\mathrm{eq}}\left({ }^{\circ} \mathrm{C}\right)$ & 2.12 & -2.85 & -0.40 \\
\hline \multirow{4}{*}{40} & $\lambda_{30 \% \mathrm{RH}}(\mathrm{nm})$ & 1552.173 & 1572.806 & 1524.888 \\
\hline & $\lambda_{90 \% \mathrm{RH}}(\mathrm{nm})$ & 1552.257 & 1572.720 & 1524.881 \\
\hline & $\Delta \lambda(\mathrm{nm})$ & 0.053 & -0.047 & -0.005 \\
\hline & $\Delta T_{\mathrm{eq}}\left({ }^{\circ} \mathrm{C}\right)$ & 2.21 & -2.08 & -0.20 \\
\hline \multirow{4}{*}{30} & $\lambda_{30 \% \mathrm{RH}}(\mathrm{nm})$ & 1552.064 & 1572.572 & 1524.623 \\
\hline & $\lambda_{90 \% \mathrm{RH}}(\mathrm{nm})$ & 1552.152 & 1572.475 & 1524.614 \\
\hline & $\Delta \lambda(\mathrm{nm})$ & 0.089 & -0.097 & -0.008 \\
\hline & $\Delta T_{\mathrm{eq}}\left({ }^{\circ} \mathrm{C}\right)$ & 3.71 & -4.29 & -0.34 \\
\hline \multirow{4}{*}{22} & $\lambda_{35 \% \mathrm{RH}}(\mathrm{nm})$ & 1551.985 & 1572.377 & 1524.415 \\
\hline & $\lambda_{90 \% \mathrm{RH}}(\mathrm{nm})$ & 1552.076 & 1572.285 & 1524.407 \\
\hline & $\Delta \lambda(\mathrm{nm})$ & 0.091 & -0.092 & -0.008 \\
\hline & $\Delta T_{\text {eq }}\left({ }^{\circ} \mathrm{C}\right)$ & 3.83 & -4.06 & -0.30 \\
\hline \multirow{4}{*}{10} & $\lambda_{50 \% \mathrm{RH}}(\mathrm{nm})$ & 1551.898 & 1572.065 & 1524.102 \\
\hline & $\lambda_{90 \% \mathrm{RH}}(\mathrm{nm})$ & 1551.953 & 1572.008 & 1524.092 \\
\hline & $\Delta \lambda(\mathrm{nm})$ & 0.055 & -0.058 & -0.010 \\
\hline & $\Delta T_{\mathrm{eq}}\left({ }^{\circ} \mathrm{C}\right)$ & 2.29 & -2.55 & -0.40 \\
\hline
\end{tabular}




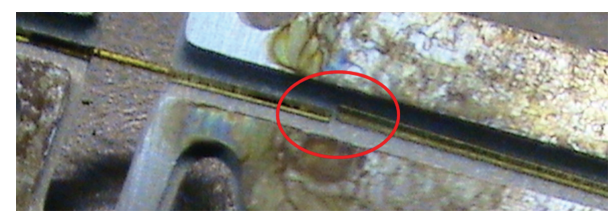

FIGURE 11: Fiber break at one end of the Bragg grating in the FBG_1 sensor.

influence that $\mathrm{RH}$ has on this carrier. If the FBG were held to the metallic carrier there should be a remarkable difference in the influence of the RH with the wavelength (such as that shown by FBG_2 sensor in Figure 10(b)). This fact explains why the wavelength shift of the FBG_1 sensor shows the opposite trend with $\mathrm{RH}$ in comparison with the rest of sensors exhibiting a linear behavior.

\section{Conclusions}

We have studied the Bragg wavelength shift due to humidity for five different FBGS and configurations. Two types of tests have been performed, with FBGS instrumented and not instrumented. In the instrumented test the FBGS spot welded to the steel specimen show an instantaneous linear behavior in their Bragg wavelength shift with changes in the RH. We have applied least square methods in order to test their linearity, obtaining good polynomial fits for the FBG inscription and for the instrumented sensor assembly (FBG + metallic carrier). A humidity variation of $60 \%$, from $30 \%$ to $90 \%$, has the same influence on the Bragg wavelength than a variation of $4.45^{\circ} \mathrm{C}$.

We have observed that an increase in the RH leads to a positive shift of the Bragg wavelength of the FBG sensor when it is detached from the metallic carrier; that is, this positive shift is due to the coating of the fiber. By contrast, the metallic carrier and the steel specimen induce negative Bragg wavelength shifts as the RH increases. In addition, we have confirmed that the positive Bragg wavelength shifts induced by the coating of the fiber are much lower compared to the negative Bragg wavelength shifts induced by the metallic carrier or the steel specimen. Therefore, the bonding material together with the specimen material induces the most dominant effects of the RH on the Bragg wavelength shift.

The FBGS epoxy bonded to both steel and CFRP specimens did show neither linear nor instantaneous behavior due to the humidity absorption of epoxy adhesives and CRFP materials. These results suggest that the absorption of humidity by the epoxy adhesive has to be investigated further, as well as the influence of humidity on the material where the sensor is instrumented.

\section{Conflict of Interests}

The authors declare that there is no conflict of interests regarding the publication of this paper.

\section{Acknowledgments}

This work has been sponsored by the institutions Ministerio de Economía y Competitividad under Project TEC201237983-C03-01 and Eusko Jaurlaritza/Gobierno Vasco under Projects IE11-302, SPE11CA001, S-PE12CA001, and IT664-13 and by the University of the Basque Country (UPV/EHU) through Program UFI11/16.

\section{References}

[1] M. Todd, L. Malsawma, C. C. Chang, and G. Johnson, "The use of FBG strain sensors in laboratory and field load tests: comparison to conventional resistive strain gages," NRL/MR5673-998418, Naval Research Laboratory, Washington, DC, USA, 1999.

[2] M. D. Todd, Fiber optic Bragg grating-based sensing [Ph.D. thesis], Structural Engineering Department, University of California, San Diego, Calif, USA.

[3] H. Guo, G. Xiao, N. Mrad, and J. Yao, "Fiber optic sensors for structural health monitoring of air platforms," Sensors, vol. 11, no. 4, pp. 3687-3705, 2011.

[4] Z. Zhou and J. Ou, “Techniques of temperature compensation for FBG strain sensors used in long-term structural monitoring," in Proceedings of Asian Pacific Fundamental Problems of Opto and Microelectronics, pp. 465-471, Khabarovsk, Russia, September 2004.

[5] Micron Optics website, http://www.micronoptics.com/sensors_ products.php.

[6] Micron Optics website, http://www.micronoptics.com/support _downloads/Sensors/Strain/os3100/.

[7] Ph. Giaccari, H. G. Limberger, and P. Kronenberg, "Influence of humidity and temperature on polyimide-coated fiber bragg gratings," in Proceedings of the Bragg Gratings, Photosensitivity, and Poling in Glass Waveguides, pp. 1-6, Institute of Applied Optics, Stresa, Italy, July 2001.

[8] S. F. H. Correia, P. Antunes, E. Pecoraro et al., "Optical fiber relative humidity sensor based on a FBG with a Di-Ureasil coating," Sensors, vol. 12, no. 7, pp. 8847-8860, 2012.

[9] J. M. Ryan, R. Adams, and S. G. R. Brown, "Moisture ingress effect on properties of CFRP," in Proceedings of the 17th International Conference on Composite Materials (ICCM '09), Edinburgh, UK, July 2009.

[10] B. de Nève and M. E. R. Shanahan, "Effects of humidity on an epoxy adhesive," International Journal of Adhesion and Adhesives, vol. 12, no. 3, pp. 191-196, 1992. 

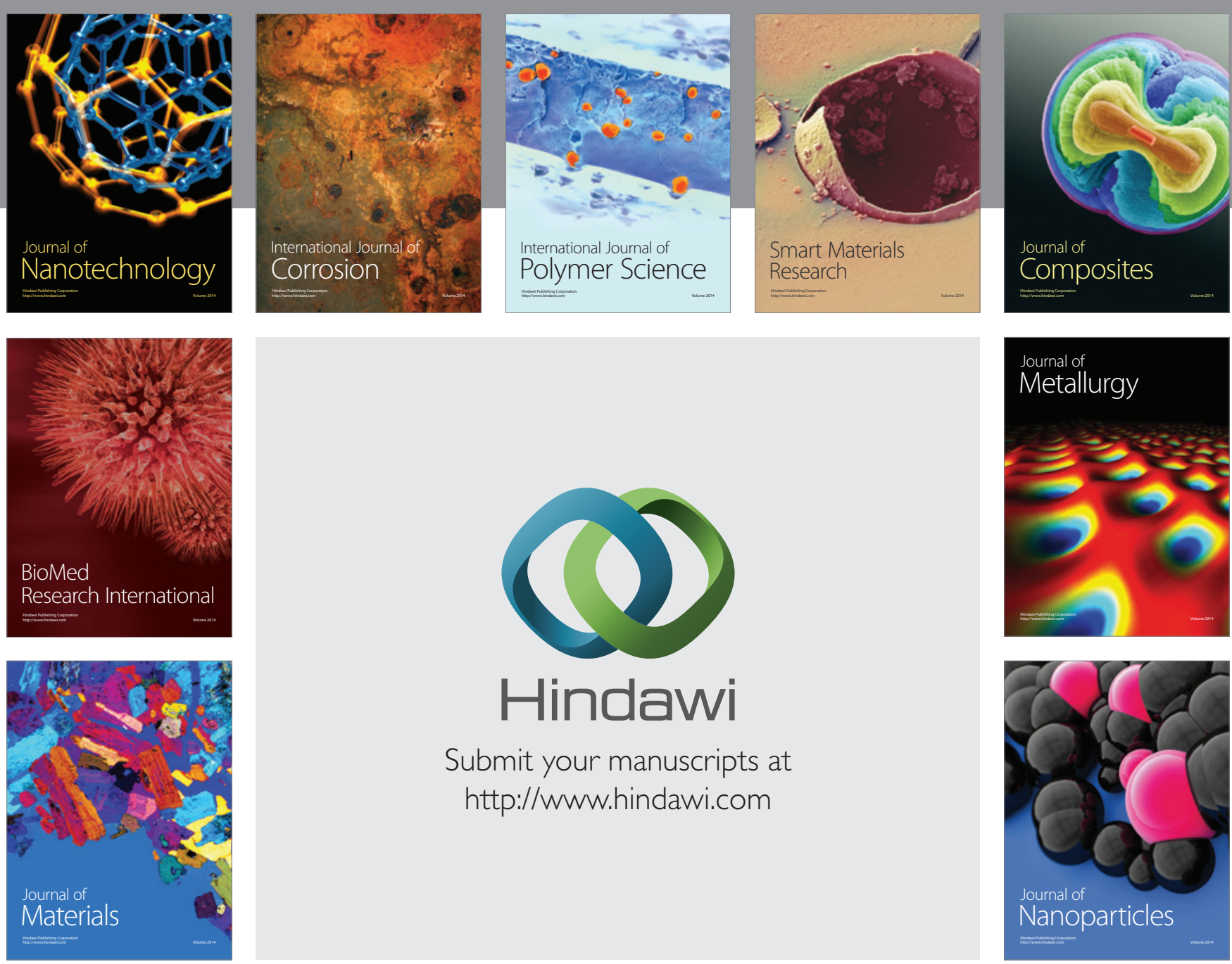

Submit your manuscripts at http://www.hindawi.com
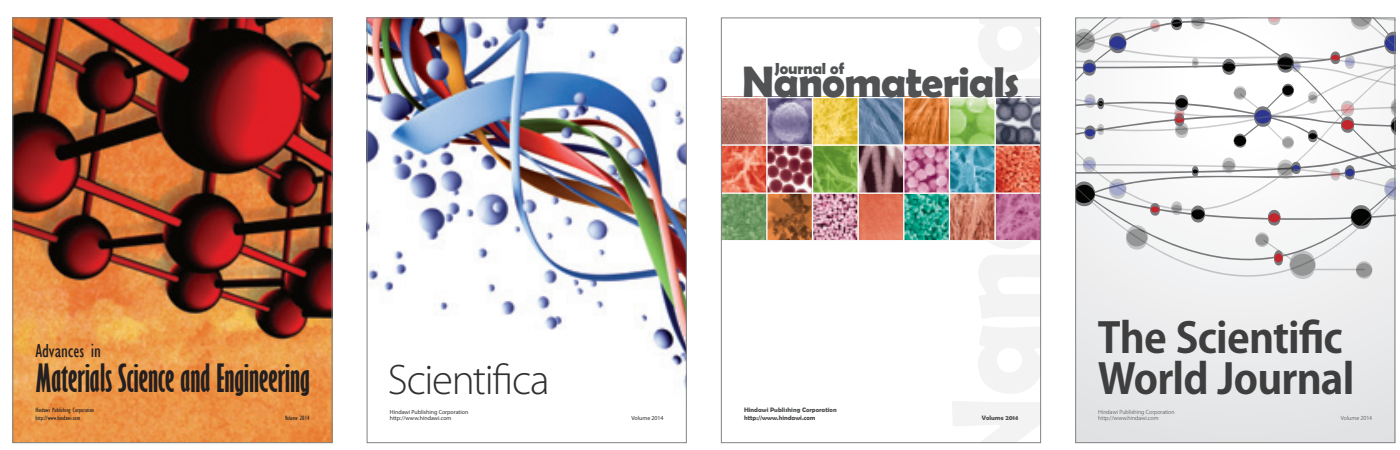

\section{The Scientific World Journal}
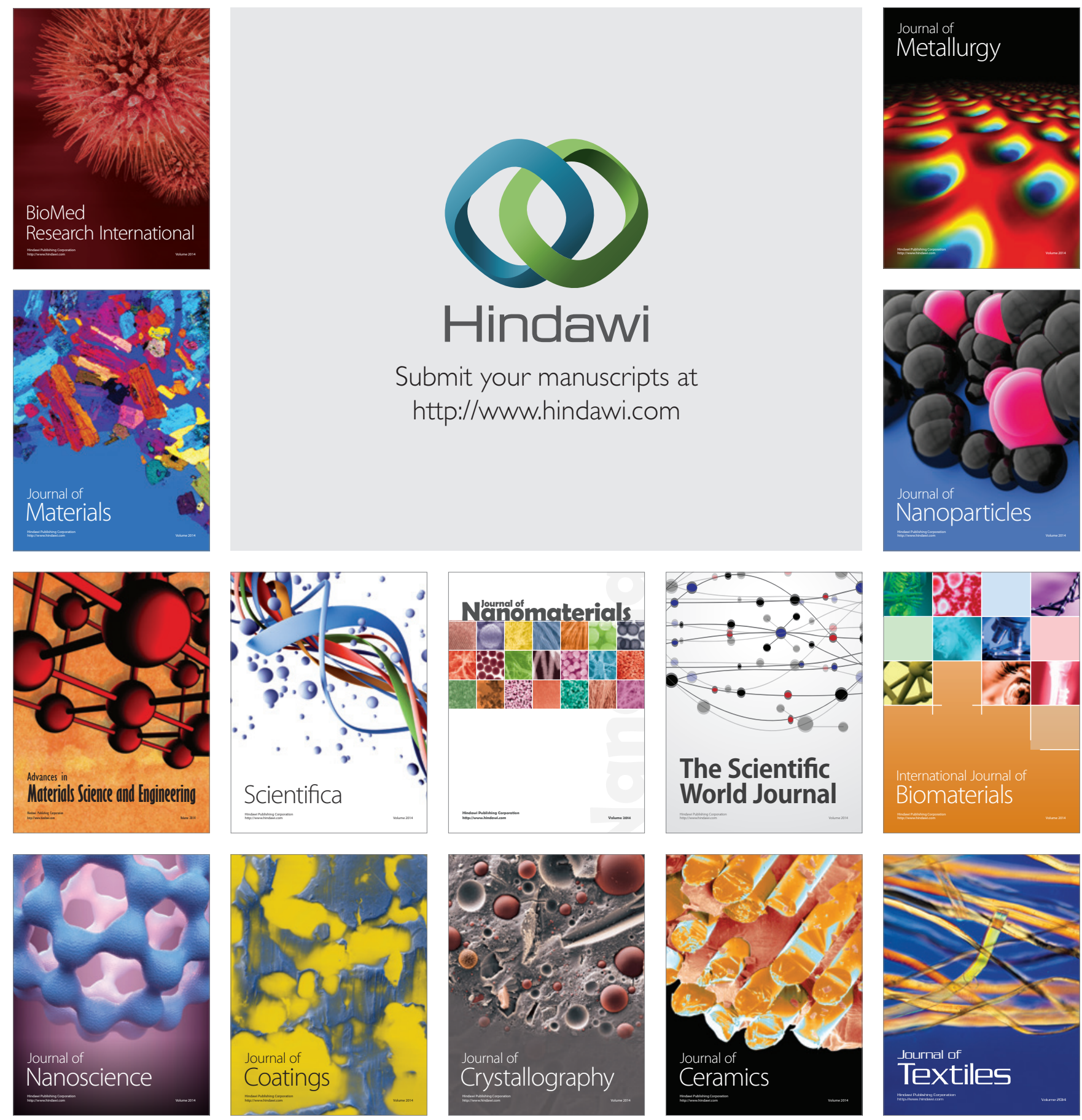